$1 \quad$ GSA Data Repository Item 2009089

\title{
Genareau et al.
}

\section{Methods Addendum}

3 Groundmass feldspar crystallinity $(\varphi)$, overall clast density ( $\rho$ ), volumetric

4 microlite density $\left(\mathrm{N}_{\mathrm{v}}{ }^{\mathrm{m}}\right)$, volumetric vesicle density $\left(\mathrm{N}_{\mathrm{v}}{ }^{\mathrm{v}}\right)$, and the thickness of

5 decompression-induced reaction rims on hornblende crystals (hbl) were determined

6 (Table 1). Groundmass feldspar crystallinity $(\varphi)$ allows an estimate of quench pressure

$7 \quad\left(\mathrm{P}_{\mathrm{F}}\right)$, which, in the case of the 1997 explosions on Montserrat, represents the depth at

8 which the magma parcel resided immediately before the explosive eruption (Fig. 2).

9 Notice that the four clasts represent a wide range of quench pressures and therefore a

10 wide range of pre-explosion depths. Clast density $(\rho)$ represents the degree and style of

11 degassing immediately prior to explosion initiation (Table 1, Fig. 2; Clarke et al., 2007).

$12 \mathrm{ID}_{\mathrm{g}}$, the solid vertical line in the depth profiles, marks the transition from plagioclase to

13 contamination on the surface of the phenocryst (glass). This point in the profile is

14 determined by an inflection in the ${ }^{39} \mathrm{~K} /{ }^{30} \mathrm{Si}$ signal where the value begins to increase

15 rapidly (Genareau et al., 2007). In some profiles, but not all, the ${ }^{7} \mathrm{Li} /{ }^{30} \mathrm{Si}$ signal begins to

16 increase at or just after this point as well. All data rimward of the $\mathrm{ID}_{\mathrm{g}}$ represents a

17 combination of plagioclase and glass, based upon the increasing incompatible element

18 concentration. $\mathrm{ID}_{\mathrm{Li}}$, the dashed vertical line, marks the point in the profile at which the

$19{ }^{7} \mathrm{Li} /{ }^{30} \mathrm{Si}$ trend changes slope and moves from constant or increasing to decreasing values.

20 Additional depth profiles not presented in the text are provided after this addendum.

21 Some of the profiles reflect two different analyses in the same crystal (e.g., ExpBi-3 and 
22 ExpBi-3x), or an analysis of a microphenocryst attached to the face of a larger crystal

23 (ExpBi-75mp).

24 Data

25 A

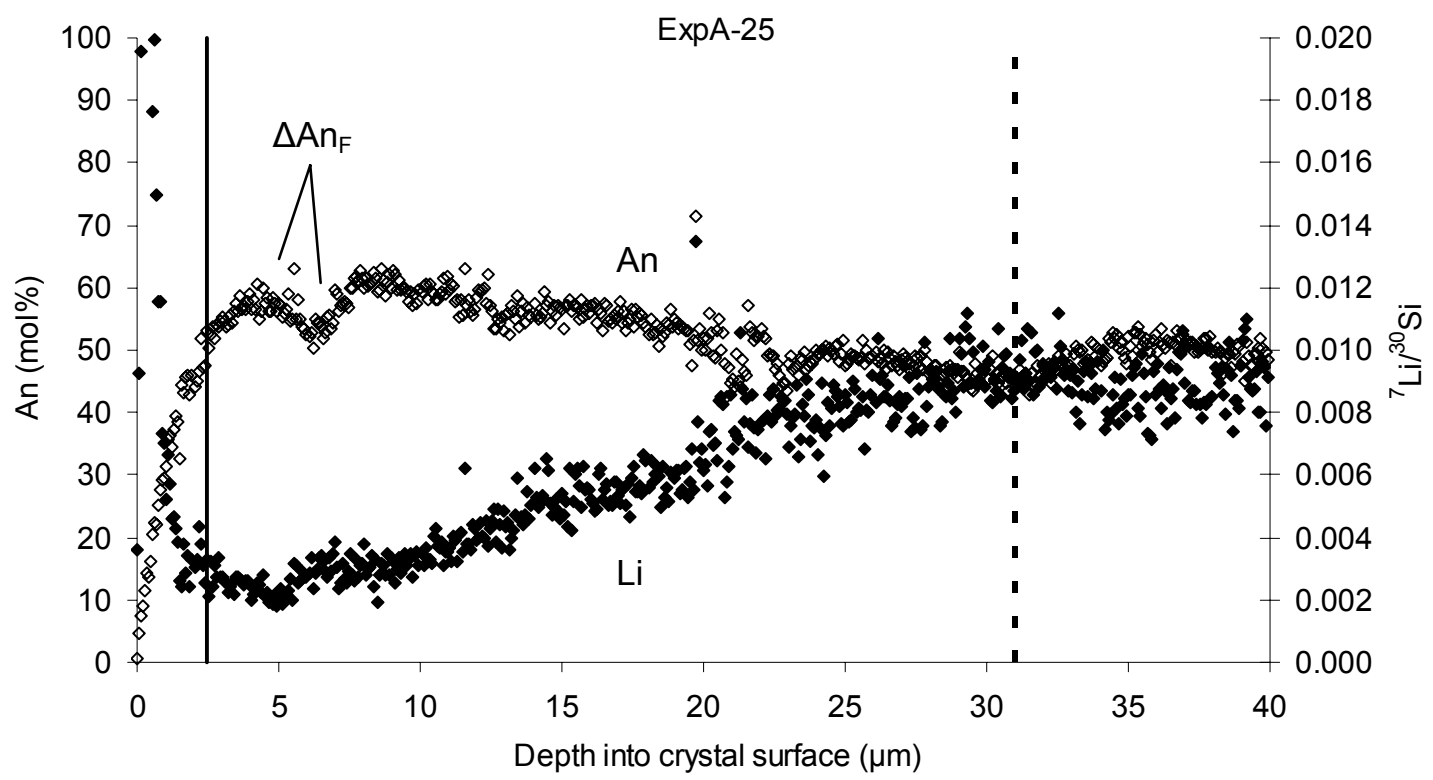



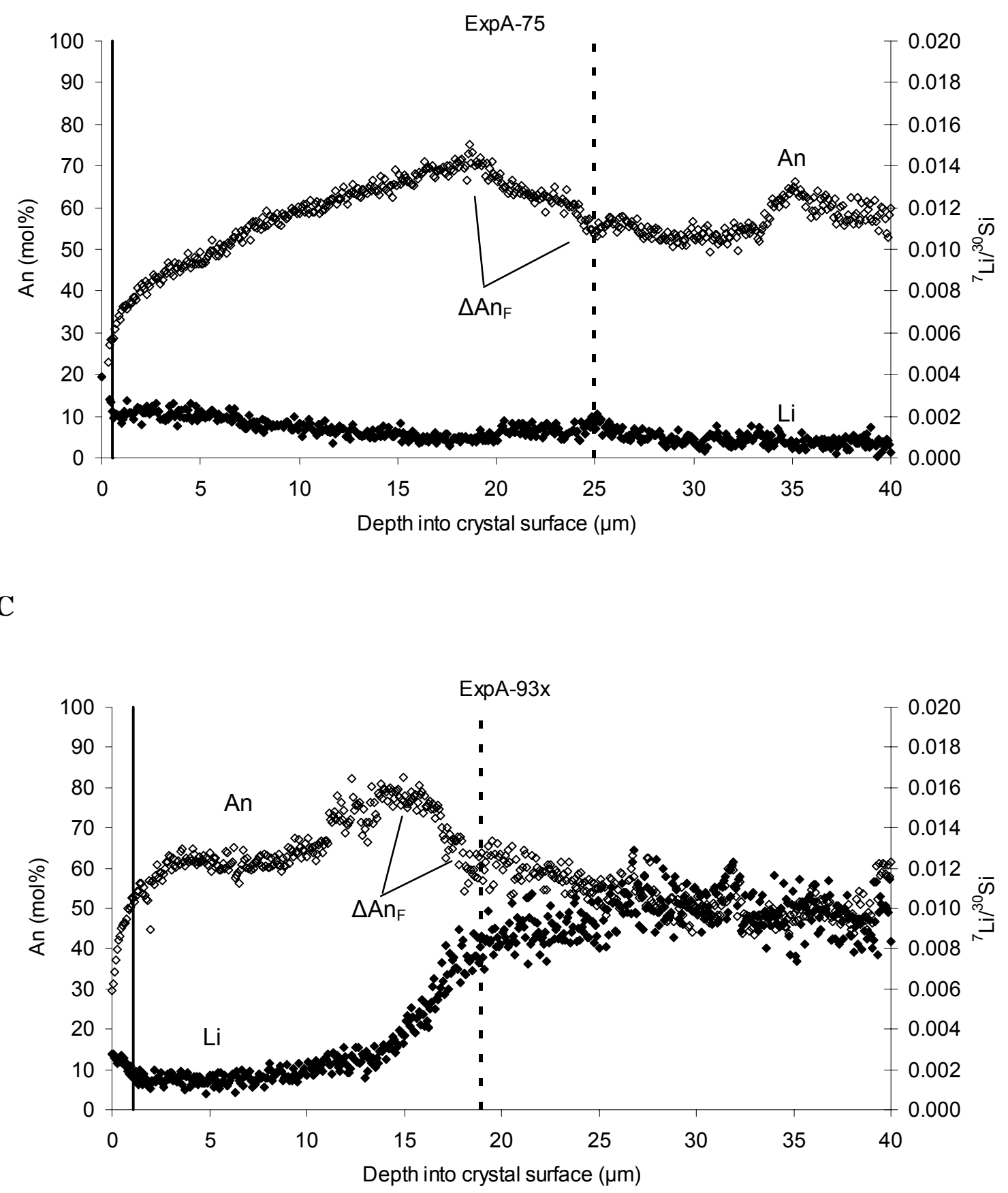


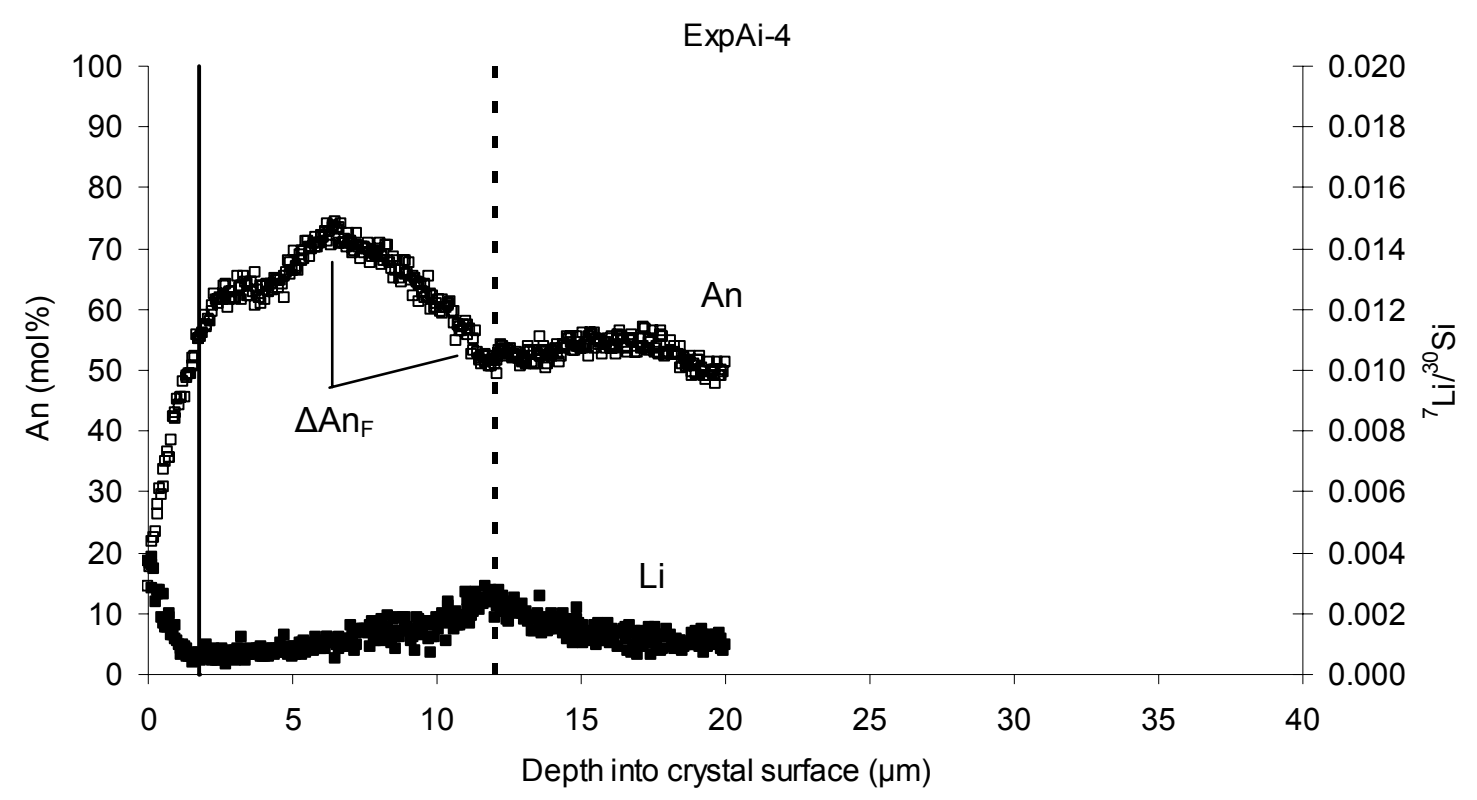

32

33

34

35 E

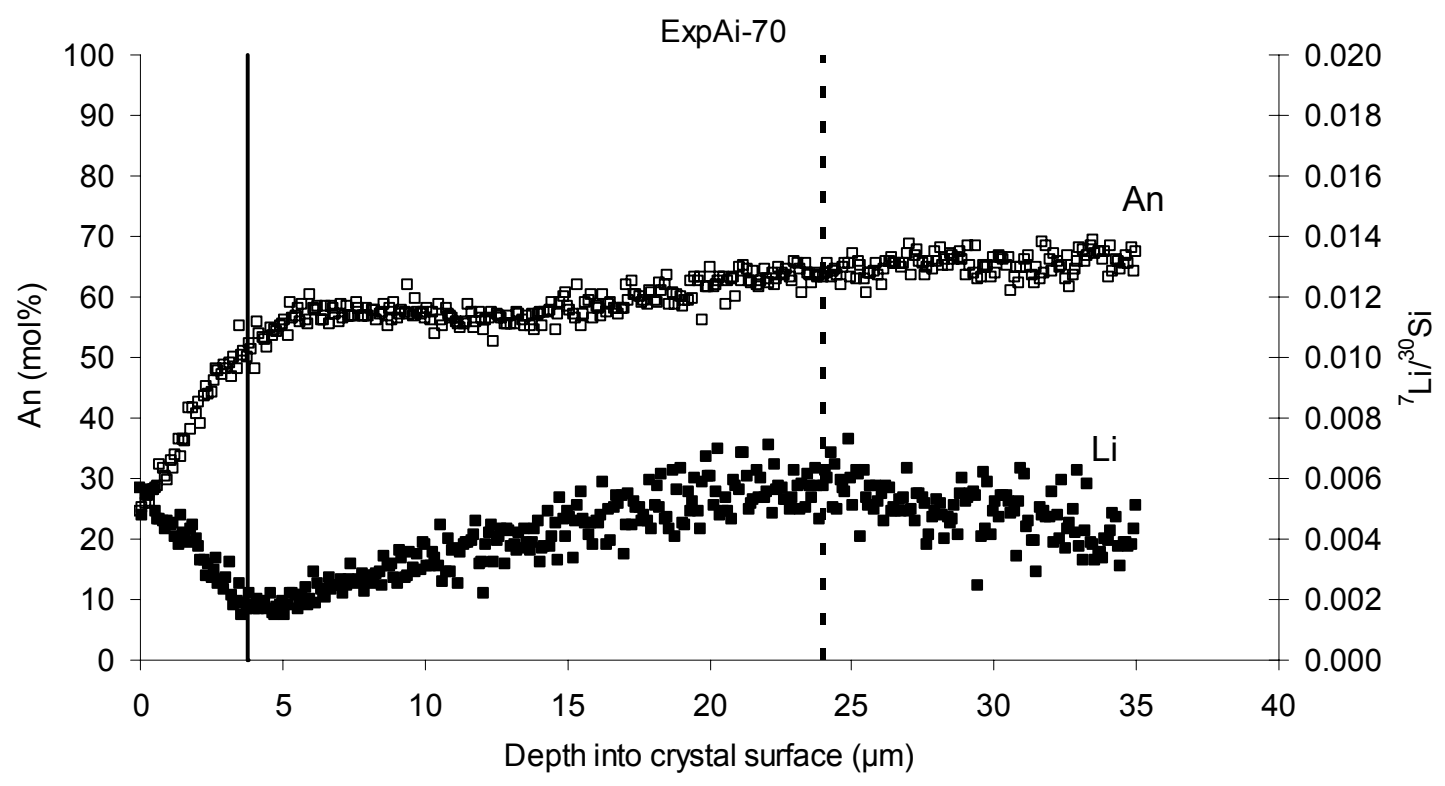




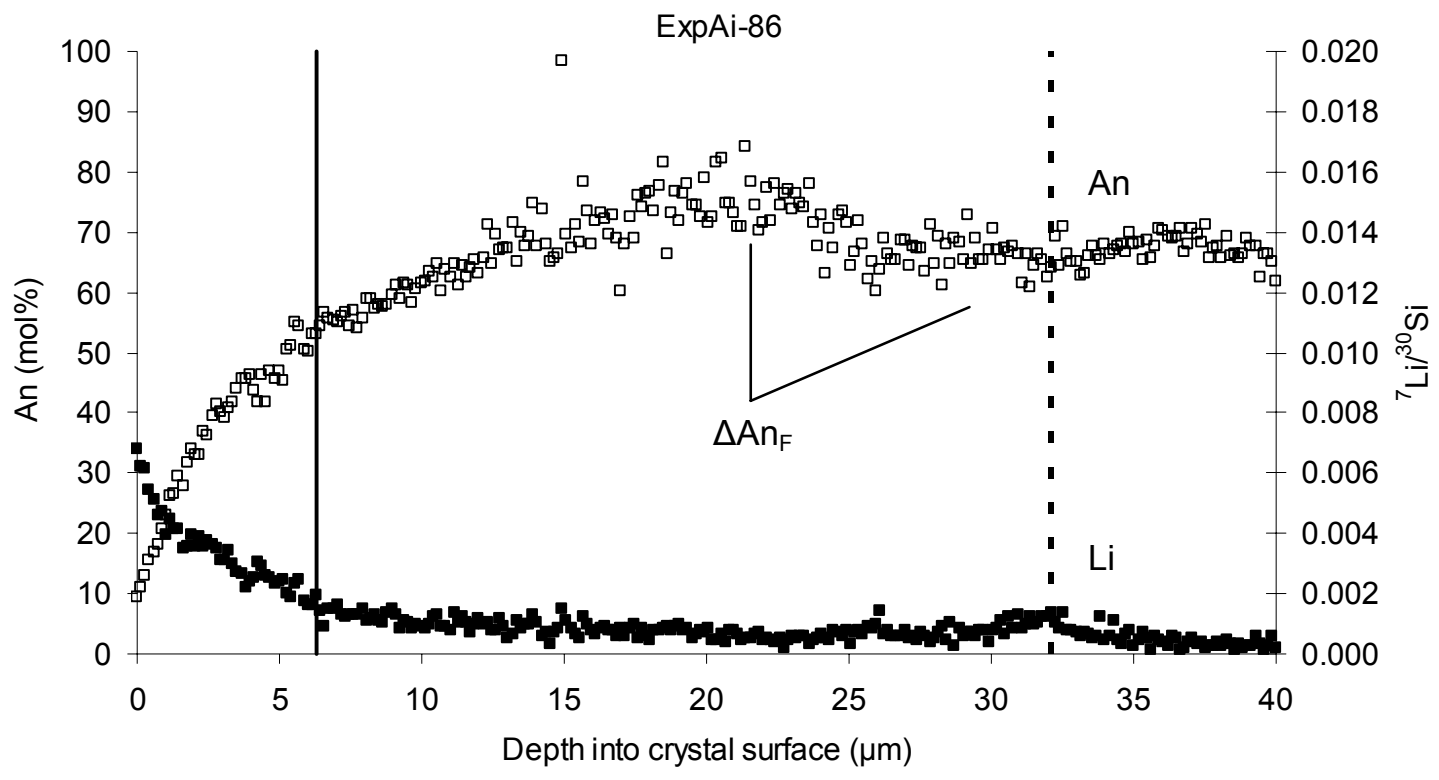

38

39

40

41

42

43

44

45

G

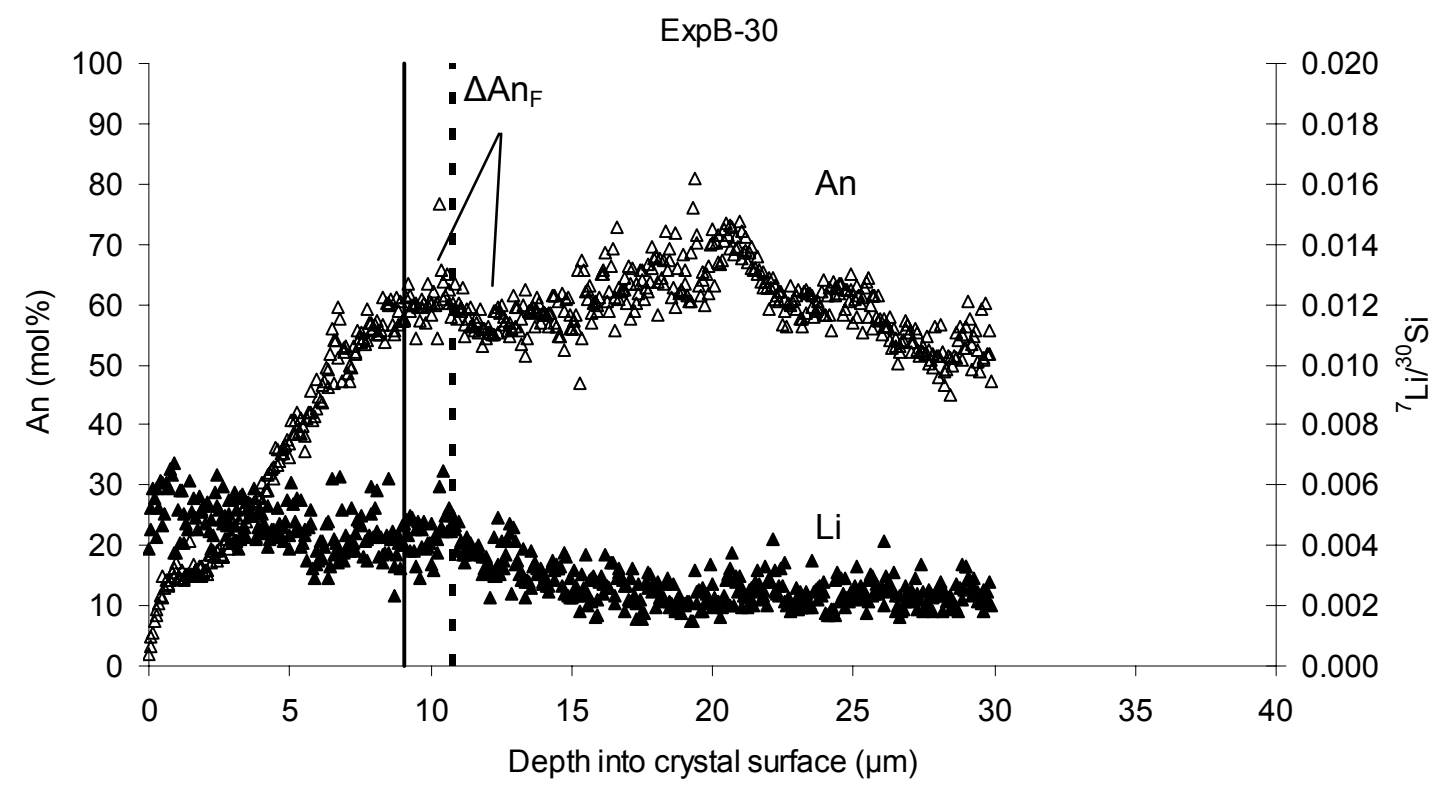

46

$47 \quad \mathbf{H}$ 


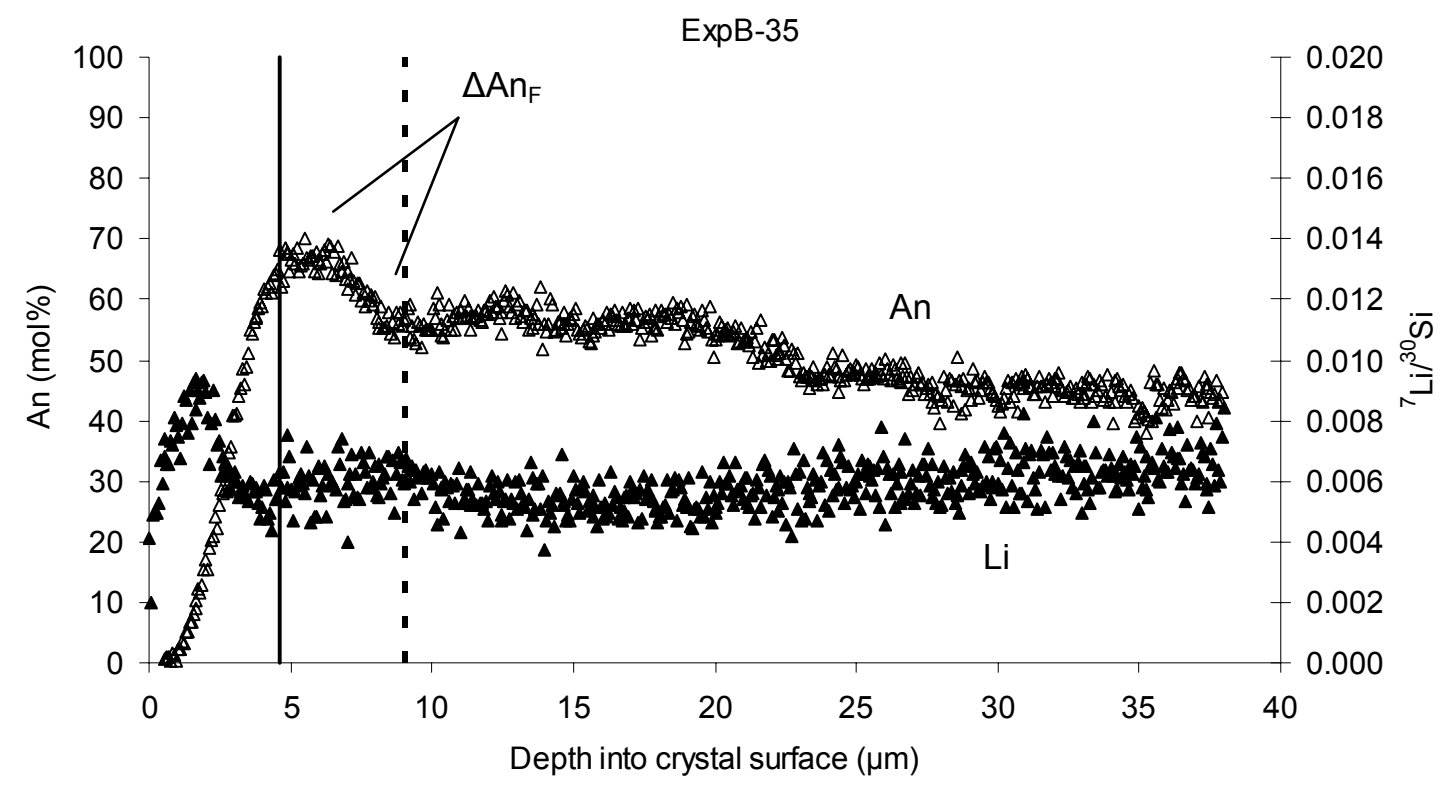

48

49

50

51

52

53

54

55

56 I

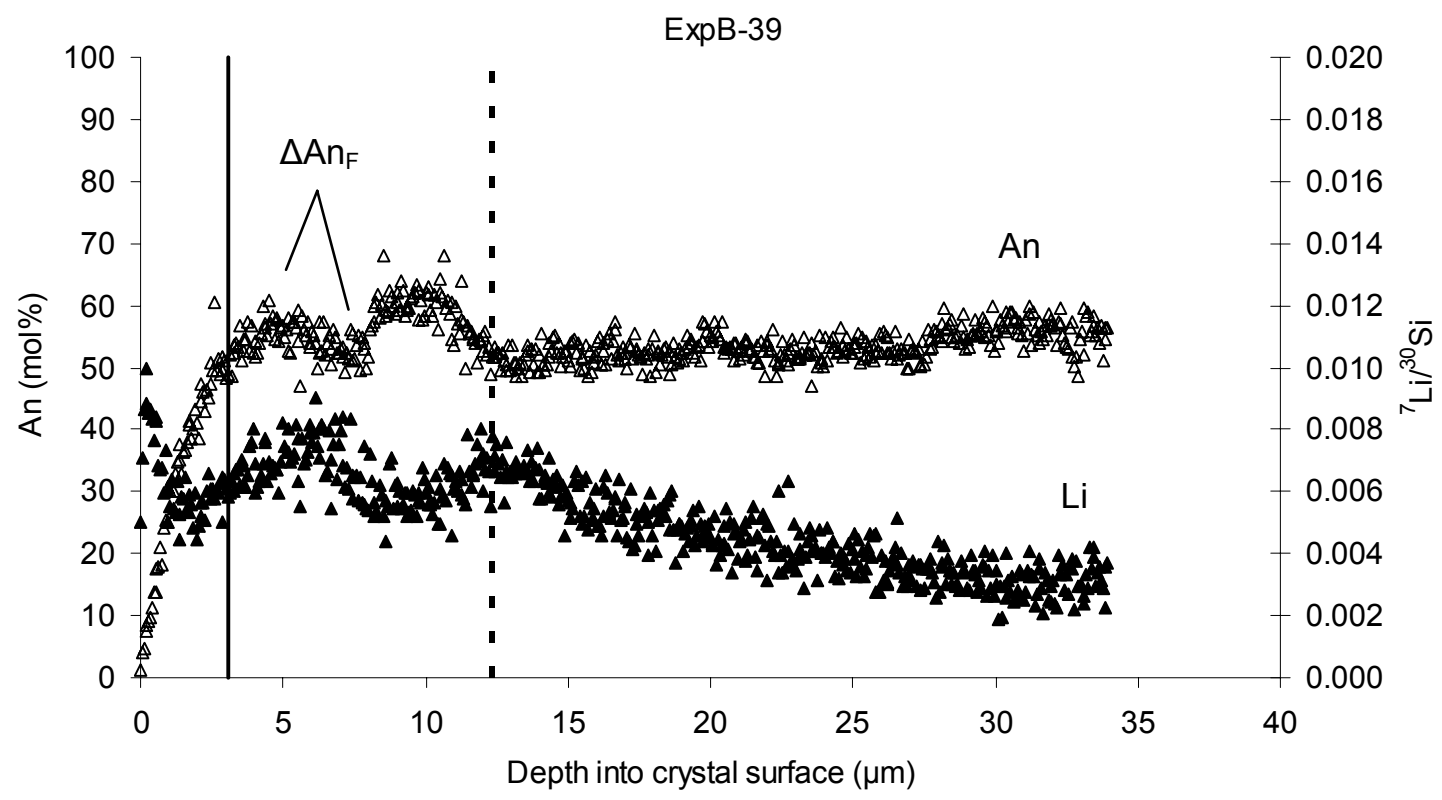


59

60 J

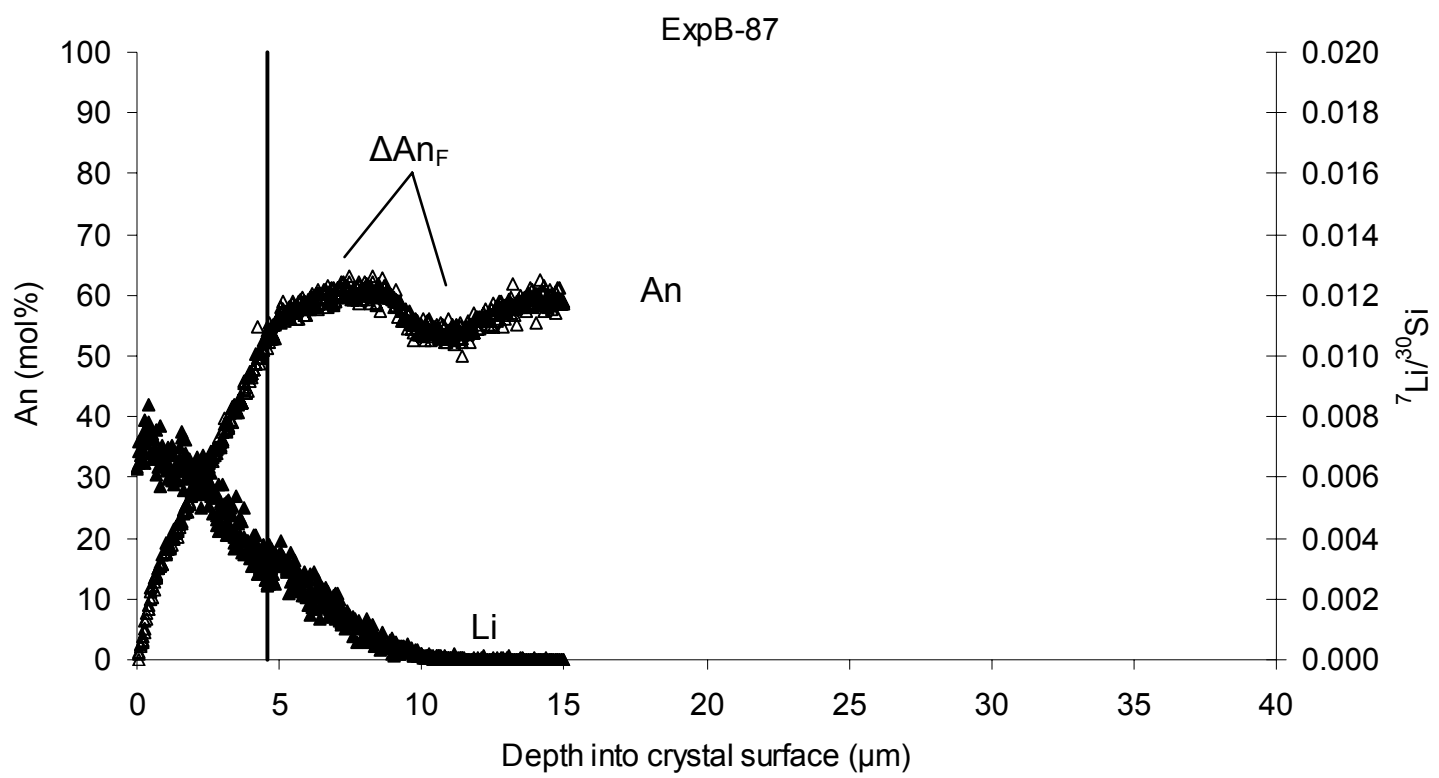

61

62

63

64

65

66

67 K

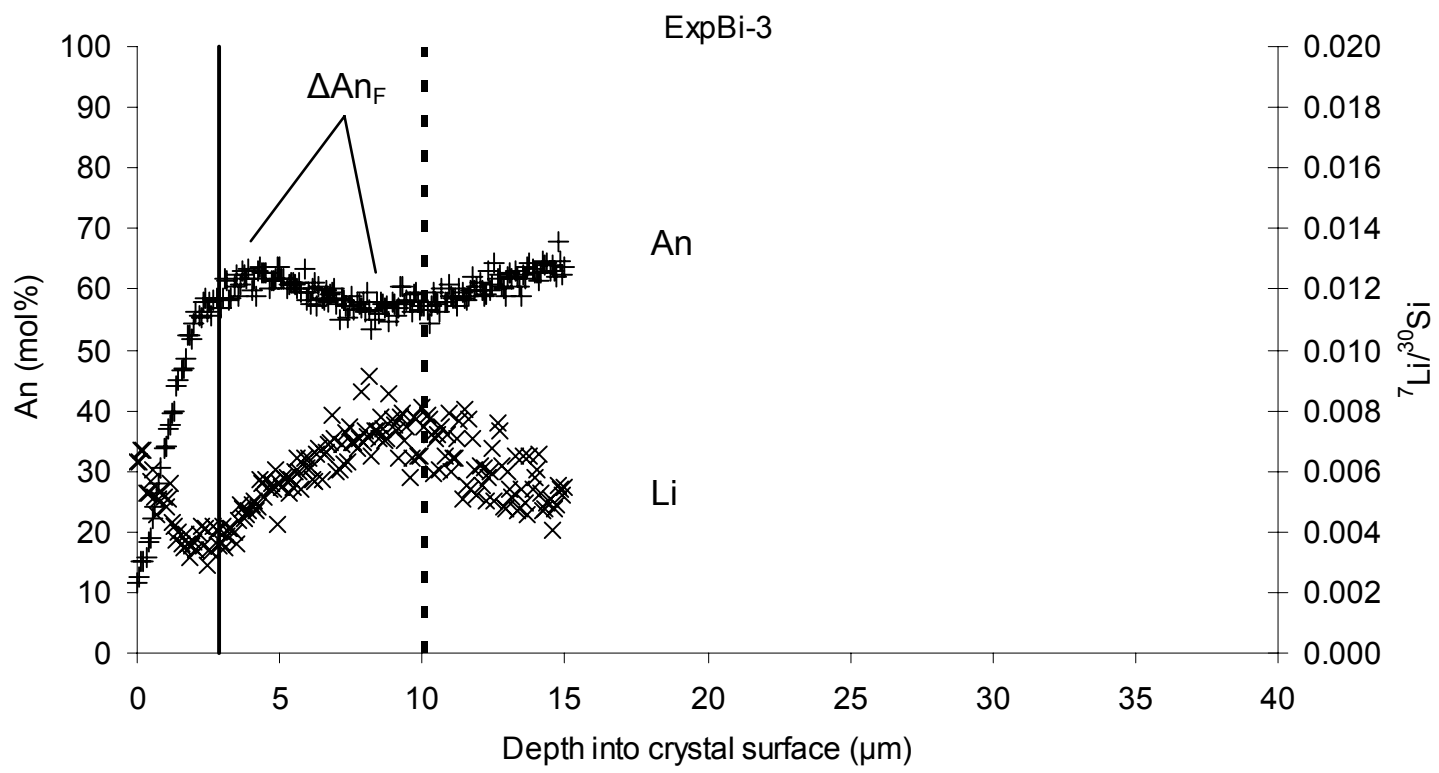

68

69 L 
70

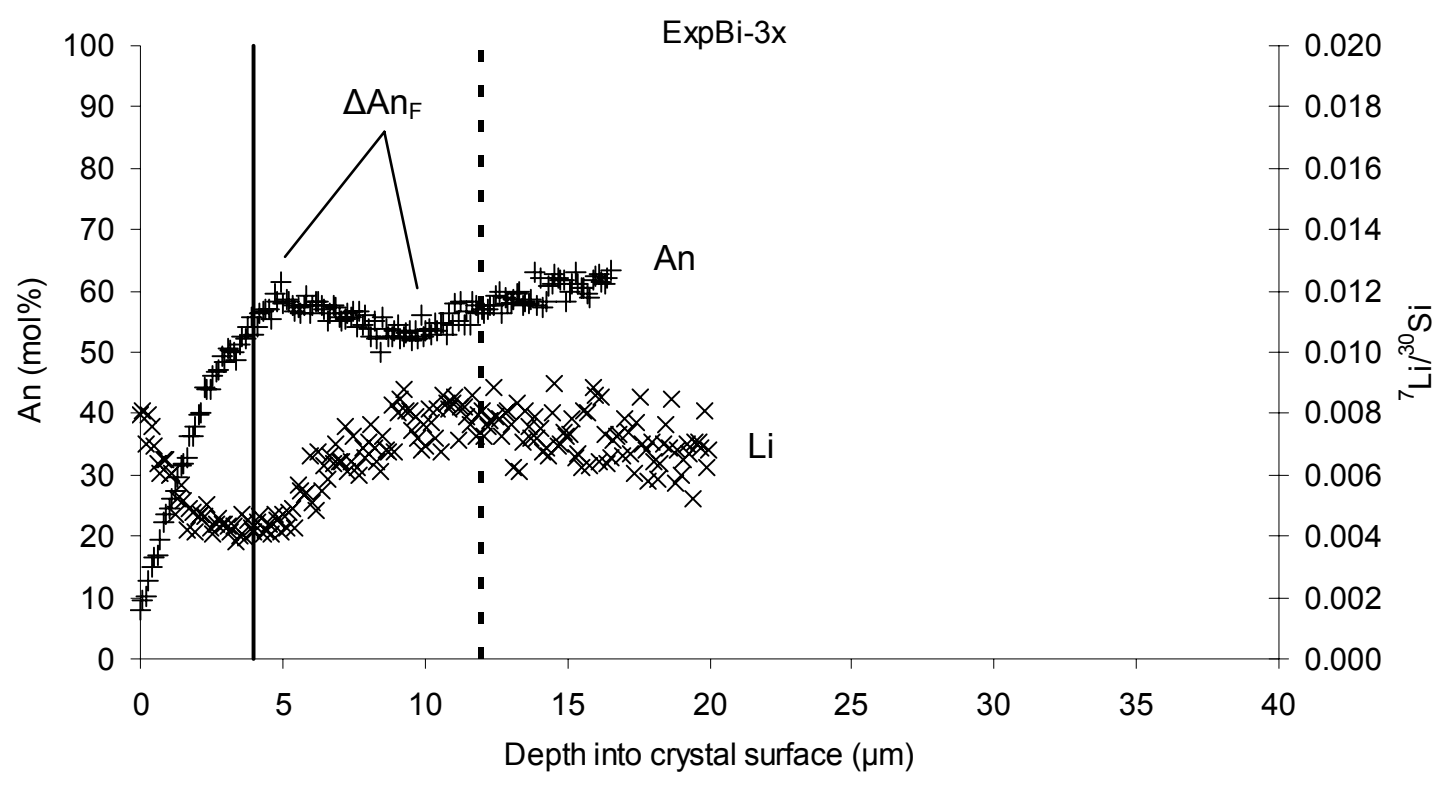

71
72

73

74

75

76

77

78 M

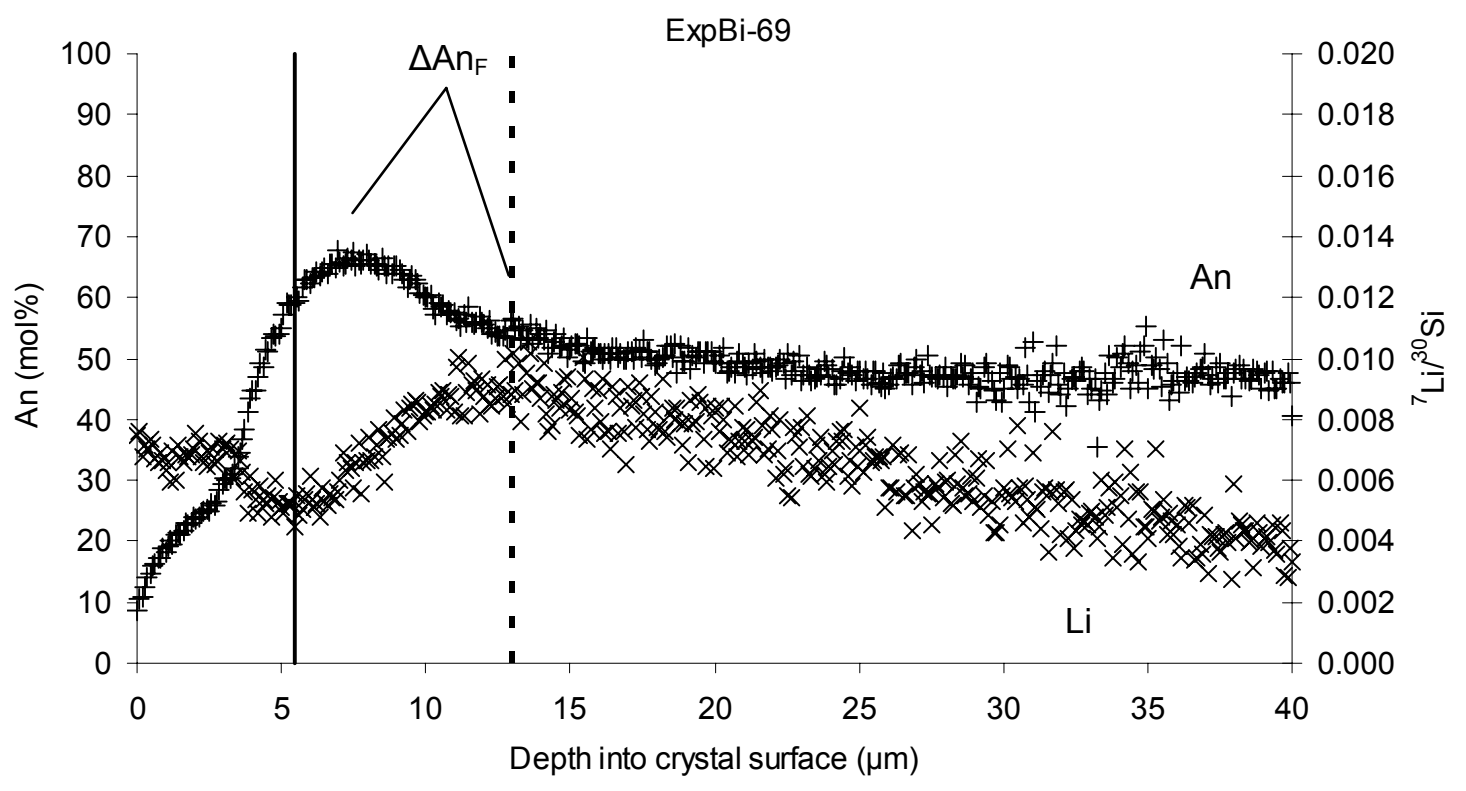

79

80 N 


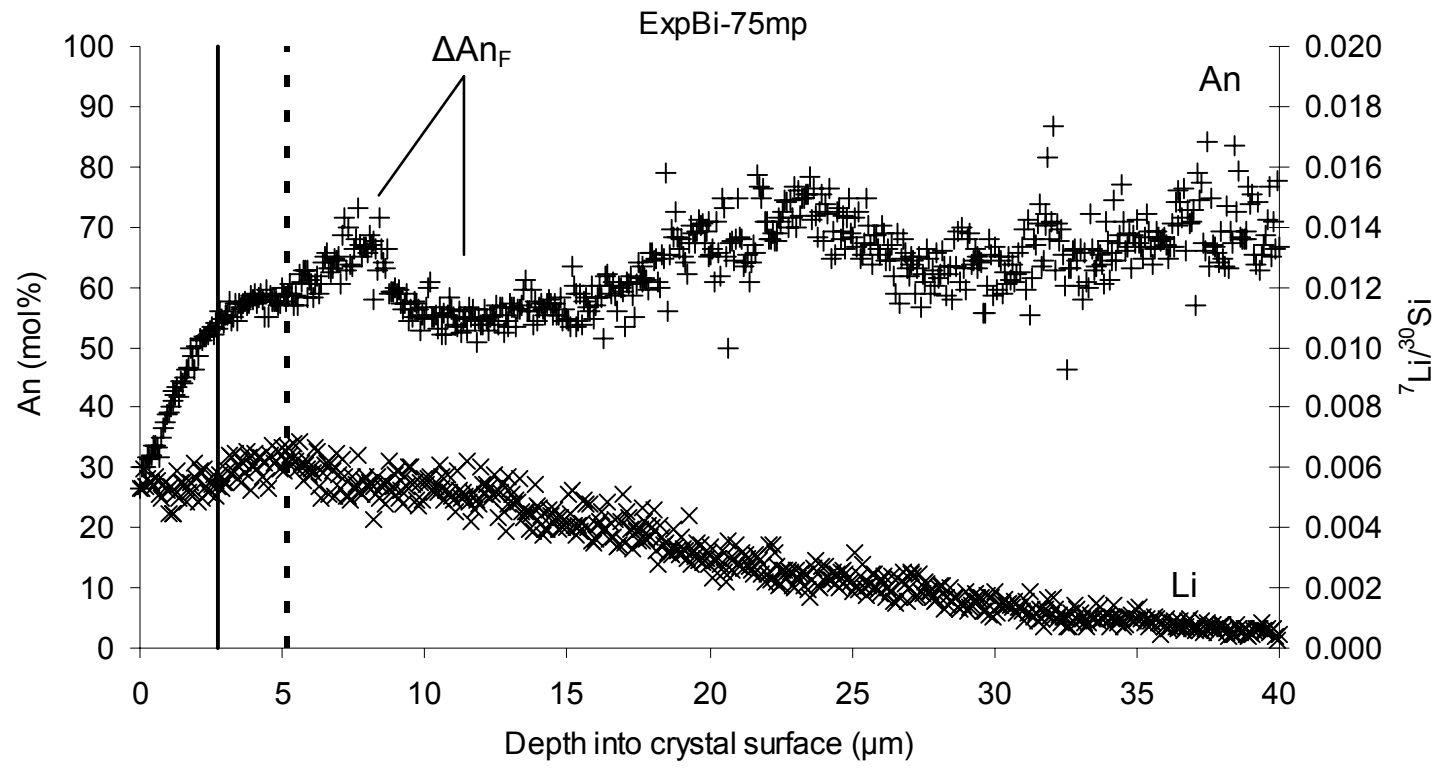

81 